\title{
Providing safe motherhood services to underserved and neglected populations in Yemen: the case for vouchers
}

\author{
Corinne G. Grainger ${ }^{1 *}{ }^{*}$, Anna C. Gorter ${ }^{2 \dagger}$, Eman Al-Kobati ${ }^{3}$ and Luke Boddam-Whetham ${ }^{4}$
}

\begin{abstract}
States of fragility and insecurity often give rise to urgent health needs that need to be met quickly and effectively, particularly for women and adolescents. Vouchers are a demand-side financing mechanism which can be used to address some of the health challenges faced by women under these circumstances. A number of organisations have begun to use vouchers to enable access to reproductive, maternal and newborn care services in conflict-affected countries such as Yemen, Syria and Central African Republic. Vouchers allow health programme implementers to use targeted subsidies to reduce financial and other barriers to accessing care, increasing and catalysing the uptake of specific health services among vulnerable and underserved populations. These subsidies are passed onto public and private providers in the form of service reimbursements and are often used to enhance capacity to meet increased demand for services, as well as to invest in quality improvements.

Yemen is one of the poorest countries in the Middle East and North Africa region, and since 2010 has consistently appeared on the lists of fragile states. We present data from the Reproductive Health Voucher Programme in Yemen to show that during 2014, when the conflict was worsening and public facilities faced significant challenges to keep functioning, the vouchers enabled women to continue accessing quality maternal newborn health services. By contracting a range of public and private providers, from referral hospitals to community midwives, the number of services utilised in one governorate in Yemen was consistently higher (17\% or more) than the predicted number for all services utilised that make up the safe motherhood voucher package. The programme was able to channel funds to facilities at a time when funds flowing to the governorates were highly erratic, enabling them to address stock-outs of drugs and supplies at the local level and to maximise the supply of critical maternal newborn health services for poor women and their families.
\end{abstract}

Keywords: Vouchers, Demand-side financing, Maternal health, Fragile states, Conflict-affected and humanitarian settings, Yemen

\section{Introduction}

Fragile and conflict-affected countries made distressingly little progress in achieving the Millennium Development Goals (MDGs), (OECD 2015; Norris et al. 2015) and the Sustainable Development Goals (SDGs) similarly fail to recognise the specific challenges they pose, particularly in terms of access to basic services (Norris et al. 2015). Among the many factors driving fragility are weak and

\footnotetext{
* Correspondence: corinnegrainger1@gmail.com

†Equal contributors

${ }^{1}$ Consultant, Yemen Reproductive Health Programme, London, UK Full list of author information is available at the end of the article
}

failing institutions, high levels of poverty and inequality and, in many parts of the world, the spread of conflict and violence. During humanitarian crises, health needs are fluid and can change rapidly, the costs of care are unpredictable and patterns of morbidity and mortality vary significantly from place to place, giving rise to complex situations which require different and often innovative solutions.

Under these circumstances, governments face significant challenges both in the provision of health services and in enabling access to services. Health challenges in conflict-affected states are particularly acute for pregnant women and their new babies (WHO 2015). Globally, some 
$60 \%$ of maternal deaths, $53 \%$ of child deaths and $45 \%$ of newborn deaths occur in settings of conflict, displacement and natural disaster (Temmerman et al. 2015).

Failing public sector services leave space for private sector providers to move in to fill the gap. In Afghanistan, for example, the private sector provides some $80 \%$ of all health care (Hanson et al. 2008). In the rush to establish access to basic services, international agencies often bypass the public sector to work through non-profit agencies and for-profit organisations for quick and visible results (Batley and Mcloughlin 2010). Insufficiently planned services, coupled with weak institutional oversight, give rise to situations where formal and informal user charges and high levels of uncertainty over costs constitute major barriers to seeking healthcare for poor people. Furthermore, the costs associated with delivering a baby in a health facility are unpredictable, since many complications of delivery are not foreseen during pregnancy.

Safe motherhood vouchers are a health financing tool which enables access to services by removing or reducing the financial barriers for women and their families, while channelling much-needed funds to service providers for quality improvements. Vouchers have a long history of use for increasing access to specific, underutilised health services among underserved or neglected populations (Gorter et al. 2012; Grainger et al. 2014). Although vouchers have been widely used to enable access to food, clothing and other shelter in conflict and humanitarian settings, the approach has not traditionally been employed to enable access to health services in these contexts (Levine and Bailey 2015). However, this has recently started to change; United Nations Population Fund (UNFPA) has used vouchers to provide access to maternal healthcare in Syria, (UNFPA 2015a), and a project in the Central African Republic (CAR) implemented by FAIRMED has used vouchers (tickets in French) to enable access to institutional delivery as part of a wider approach to improving the health status of Aka and Bantu women and their families living in temporary settlements. ${ }^{1}$

Systematic reviews point to strong evidence that vouchers increase utilisation of services and modest evidence that vouchers can target specific groups for service delivery and improve the quality of services, although the modest evidence largely stems from the small number of robust studies rather than a lack of impact on quality (Brody et al. 2013; Bellows et al. 2011; Gorter et al. 2013). Some more recent evidence points to improvements in both the quantity and quality of care provided by voucher service providers (Watt et al. 2015; Kanya 2013).

In this article, we look at the use of vouchers for enabling access to safe delivery services in fragile settings, using the Yemen Reproductive Health (RH) Voucher Programme as our case study. Vouchers were used in Lahj Governorate in Yemen to catalyse uptake of safe motherhood services during 2014; a year when the security situation deteriorated further in the country and funds flow to public health facilities in the governorates was highly unpredictable. Using analysis of data from this programme, as well as lessons from other voucher programmes, we suggest that flexible demand-side approaches such as vouchers are well suited to the uncertainties of working in difficult and fragile contexts.

\section{Country context}

Yemen is one of the poorest countries in the Middle East and North Africa (MENA) region, and since 2010 has consistently appeared on the lists of fragile states and conflict-affected areas (World Bank 2015; Messner et al. 2015; United Nations Office for the Coordination of Humanitarian Affairs (OCHA) 2015). It is now estimated that 18.8 million people (nearly $70 \%$ of the population) require humanitarian assistance to meet their basic needs or protect their fundamental rights, while some 15 million people lack sufficient access to healthcare (OCHA 2015). During 2014, the security situation in Yemen continued to deteriorate with consequences for the functioning of government institutions and structures; state funds became restricted, with highly erratic fund flows from the central government to the governorates.

Giving birth is a risky business for Yemeni women; maternal mortality is high, particularly in rural areas which are home to $70 \%$ of the population (CSO Yemen 2007) and where 164 women die for every 100,000 live births (Yemen National Health and Demographic Survey (NHDS) 2015). While some progress had been made prior to the conflict, Yemen has the lowest level of antenatal care coverage in the region; women continue to encounter multiple barriers to uptake of institutional delivery and most mothers still deliver at home (Yemen NHDS 2015). According to the data from the most recent National Health and Demographic Survey (NHDS) for Yemen, $34 \%$ of Yemeni women in rural areas give birth with the help of a skilled birth attendant compared with $73 \%$ in urban areas, while only $23 \%$ of rural women deliver at a health facility (Yemen NHDS 2015). Four in five women responding to the NHDS reported that a major problem in accessing health care was not wanting to go alone, and about three in five indicated that lack of a female provider and distance to a health facility were problems (Yemen NHDS 2015). The worsening conflict means that the ability of women to access care is likely to have deteriorated significantly since 2013 when the data were collected. 
Yemen's health system is dominated by the public sector; while those on higher incomes in urban areas benefit from a strong and growing private sector, rural areas are reliant on underfunded public health facilities. Fees are paid for maternal health services at all levels and contribute to high financial barriers, which also include costs of travel and subsistence while away from home. High and uncertain costs, long distances to facilities and high levels of insecurity combine to place the health and life of pregnant women and their unborn babies at considerable risk when travelling to a health facility.

Against this backdrop, the Yamaan Foundation for Health and Social Development in Yemen (Yamaan), with support from Options Consultancy Services (Options), developed a voucher programme that facilitates access to a highly subsidised package of reproductive and safe motherhood services for poor Yemeni women in two governorates. In addition to services, the vouchers provide access to free transport to the health facility for delivery and a contribution towards the costs of accommodation and food for a chaperone. In this way, the vouchers reduce financial and other barriers to accessing care while channelling funds to contracted public and private service providers that can be used to fill financing gaps at the local level and improve service quality.

\section{Vouchers and how they work}

In this demand-side financing approach, the funds flow via clients to health providers, based on the provision of services in a fee-for-service model (see Fig. 1). A Voucher Management Agency (VMA) is appointed to manage the programme-a contracted third-party agency or a government agency-and receives funding and contracts and reimburses service providers. As a managing agent, the VMA is responsible for printing and distributing the vouchers, often employing or contracting local voucher distributors who visit communities, counsel potential clients and hand out the vouchers. While there is sometimes a nominal fee for the voucher itself, services for the voucher holder are usually free at the point of delivery, removing the uncertainty over costs. The structure of a voucher programme is, in many ways, similar to that of an insurance programme, and vouchers are sometimes viewed as paving the way for the introduction of social health insurance. The original justification for charging a nominal fee for the voucher was to introduce the concept of pre-payment for services. However, in fragile and conflict-affected settings, even small fees are often waived. The VMA is also responsible for monitoring, checking claims and preventing gaming and fraud. Funds can also be paid directly to transporters, often using mobile money.
Vouchers can be used for a range of services and have most commonly been used to improve access to reproductive health services such as family planning and safe motherhood services (Gorter et al. 2012; Grainger et al. 2014).

The distribution of vouchers in the community presents an opportunity to provide information on important aspects of the subsidised health services (where, what and why), often during face-to-face meetings at women's homes. Although little research has been done into this aspect, it is thought that the voucher acts like an invitation, empowering the client to seek services and providing proof-in-hand that they will be attended to free of charge, and not sent home.

In this way, vouchers can also help to combat stigmatisation of marginalised groups by conferring a value on each voucher holder (the voucher reimbursement), as well as overcome cultural and social barriers to access. This effect was demonstrated in the aforementioned project in the CAR where vouchers were successfully used to enable and encourage access to maternal and newborn care for Aka and Bantu women living in temporary settlements. This was achieved despite the beliefs of programme staff that vouchers would not be able to overcome the traditional mistrust of the health services, and cultural beliefs and norms which keep women delivering at home. ${ }^{2}$

The success of undertaking voucher distribution in communities can be seen in the high proportion of vouchers which are then utilised by women, despite what are often thought to be intractable barriers to access arising from the complex interaction of cultural, ethnic and socioeconomic factors. In Lahj during 2014, nearly $70 \%$ of women used their vouchers to access

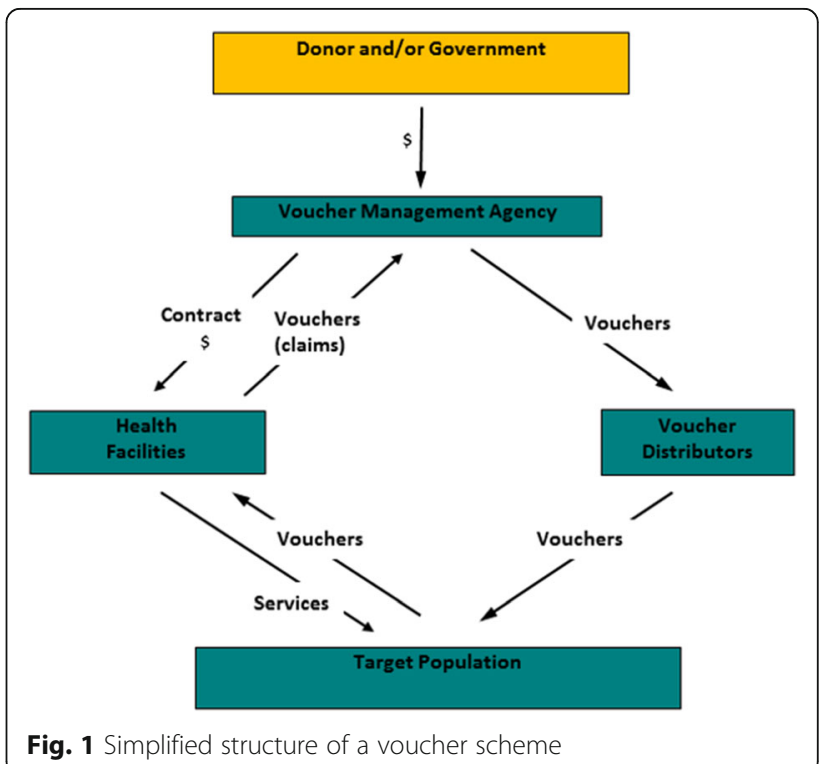


services at a contracted health facility despite the worsening security situation which made travel difficult and often dangerous. In voucher programmes in non-fragile settings, this proportion is often higher (Gorter and Bayou 2011). The vouchers also act as a form of insurance for women, providing access at a future date to quality services at no cost, whether or not women experience complications related to the delivery of their babies.

On the supply-side, service providers are keen to attend to voucher holders because each one represents a reimbursement payment. Experience from a number of reproductive health voucher programmes shows that over time, providers tailor their services and become more responsive to the needs of the target group, with the aim of attracting more women (Gorter et al. 2013; Gorter and Bayou 2011). Reviews of voucher programmes show that the reimbursement funds are used for a range of purposes by participating facilities, including additional training for staff, purchase of critical supplies such as for infection prevention, and to make facilities more welcoming (increased privacy, improved hygiene and so on) (Gorter et al. 2012; Grainger et al. 2014; Kanya 2013).

In addition to removing user fees at the point of delivery, voucher programmes can, through the strategic contracting of public and private providers, reduce distances to facilities and associated travel costs, as well as maximise capacity from existing service providers. The Yemen and Kenya (Gorter and Bayou 2011) RH voucher programmes saw new providers upgrade their services in order to participate in the project, thus increasing local capacity to attend to women.

Vouchers can help to ensure and improve quality by assessing providers and stipulating minimum standards of care for entry to the scheme. As quality is assessed on an annual basis, the design can be flexible and adapted to difficult working environments; providers which do not meet the minimum standards can be given a chance and hence an incentive, to improve quality and be contracted at a later stage.

\section{Programme description}

Financed by the German government through the German development bank, Kreditanstalt für Wiederaufbau (KfW), the Yemen Reproductive Health Voucher Programme began implementation in 2013 and operates in two governorates, Lahj in the south and Ibb in the centre of the country. Lahj is one of the poorest governorates in the south of Yemen and is currently suffering from critical food insecurity (OCHA 2015). The governorate has, however, benefited from a relatively functional public health system, supported by a motivated health team interested in developing new approaches to improve the health status of people living in Lahj.

As the programme is focused in rural areas, it is run predominantly through the public sector and in close coordination with the governorate and national ministries of health. A national NGO, Yamaan Foundation, acts as the voucher management agency, contracting a range of providers from hospitals to rural health units and independent community midwives; around a quarter of these are private sector providers. Yamaan assesses and recruits service providers and provides training in voucher programme administration, organises quality assurance and, where gaps are identified, facilitates clinical training of staff. The service agreements which underlie the relationship between the managing agency and contracted providers set out detailed conditions for participation in the scheme, including minimum levels of service quality based on signal functions, and reimbursement prices for services provided.

Locally contracted voucher distributors identify eligible women in the community, provide them with information on the importance of safe motherhood services and sell vouchers to clients at a heavily subsidised price of 200 Yemeni rials (less than one US dollar). A proportion of the vouchers distributed (around 15\%) are currently fully subsidised for those who cannot afford this low fee. The voucher provides free access to the full package of safe motherhood services, including four antenatal care (ANC) visits, safe delivery including management of complications and caesarean section, two postnatal care (PNC) visits and postnatal family planning services. Free transport to a health facility for delivery and, in case of a complication, a contribution towards costs of accommodation and food for a chaperone are also included in the package. A second type of voucher for family planning is distributed for free and entitles women to a free family planning method of her choice, follow up for any complications and removal if and when required.

\section{Method and results}

As an output-based or results-based approach, voucher programmes have strong inbuilt data collection and analysis mechanisms. Data on targeted services are collected, and trends in service utilisation are analysed as an integral part of voucher system monitoring. In order to estimate the effect of the vouchers on service utilisation, the analysis presented below takes selected project data on service uptake in the Governorate of Lahj in 2014 and compares these data to expected levels of service uptake. Comparison data are scarce for Yemen; due to the security situation, the authors were unable to travel to Yemen to collect additional primary data. Furthermore, Yemen does not currently benefit from a health management information system (HMIS) that 
provides accurate or complete data on health service provision in the country.

Expected uptake of services was calculated using the utilisation rates observed in the NHDS which was implemented in 2013 (Yemen NHDS 2015). In the context of the Yemeni conflict, an assumption was made by the authors that in the absence of external support, utilisation of maternal newborn health services was unlikely to have increased between the collection of the Yemen NHDS data in the mid 2013 and 2014 when the programme data were collected and analysed, thereby providing a robust comparison point. The data on the actual uptake of services in the voucher project are drawn from an existing project database where all data are anonymised.

The project had permission from the Yemeni Ministry of Public Health and Population (MOPHP) to monitor and collect these data, as set out in the financing and separate agreements between the Governments of Germany and the Republic of Yemen.

Data presented here are for the Lahj Governorate where the voucher programme was first introduced and then scaled up in phases from April 2013 to September 2014 when all 15 districts in Lahj finally participated in the programme. In April 2015, the voucher distribution was stopped but service provision continued until the last distributed voucher had been used at the beginning of 2016. From April 2013 to April 2015, around 50,200 safe motherhood vouchers were distributed in Lahj, as shown in Table 1. There was no requirement to use the voucher immediately; however, more than half of women used their voucher within 2 months, while some used their voucher relatively late in their pregnancy and some months after they had received it.

Data up to January 2016 show that a total of some 32,500 safe motherhood vouchers have been redeemed. In April 2015, the conflict deteriorated further with heavy fighting in Lahj for several months. This caused serious problems in the supply chain as well as damage to health facility buildings, and many providers in Lahj had to close temporarily at some point during 2015, leading to declining voucher redemption rates over time (i.e. the proportion of distributed vouchers which are then utilised for service delivery). Table 1 shows that the redemption rate for safe motherhood vouchers distributed in 2013 was $88 \%$, and for those distributed in 2014 and 2015, it was respectively $68 \%$ and $42 \%$ respectively. The overall redemption was $65 \%$ which means that $65 \%$ of women who received a voucher subsequently went on to use their vouchers for health services.

As in many fragile environments, accurate population-based data in Yemen are hard to obtain and often not available. The estimated total population in Lahj in 2014 was 912,709, calculated using population data from the most recent census in 2004 (CSO Yemen 2007) and correcting for population growth. The programme pilot tested a povertytargeting approach in four of the 15 districts of Lahj, where it excluded the majority of non-poor women (defined as the highest two socioeconomic quintiles), while in the other 11 and much poorer districts, all women were eligible. Excluding the non-poor population in the four districts with poverty-targeting, the eligible population in the governorate was deemed to be 809,379 , calculated by excluding $40 \%$ of the estimated population in the four districts with the poverty-targeting approach.

Table 2 presents the results of the comparison of expected uptake of safe motherhood services in the governorate, with the actual number of services provided through the $\mathrm{RH}$ voucher programme.

Using the crude birth rate of $3.62 \%$ from the NHDS for Yemen (Yemen NHDS 2015), we estimated the expected number of deliveries among eligible women in 2014 in Lahj to be 29,300 deliveries. However, because the programme did not reach full scale until September 2014, this number had to be corrected for the period of time in which eligible women had access to vouchers that they could use. We calculated this number by using only the person months that eligible women were covered by vouchers in 2014 . This was $64 \%$ of all person months in 2014. Therefore, the expected number of deliveries during the period under review was estimated to be 18,644 (64\% of 29,300 ).

We then calculated the number of women expected to make use of the different services covered by the safe

Table 1 Vouchers distributed and vouchers utilised in 2013, 2014 and 2015 in Lahj

\begin{tabular}{llll}
\hline & No. of SM vouchers distributed & No. of SM vouchers utilised of those distributed in a certain year & Redemption rate \\
\hline 2013 & 5038 & 4416 & $88 \%$ \\
2014 & 34,852 & 23,767 & $68 \%$ \\
2015 & 10,346 & 4346 & $42 \%$ \\
All years & 50,236 & 32,529 & $65 \%$ \\
\hline
\end{tabular}

Redemption rate is the percentage of vouchers distributed which are subsequently utilised for a safe motherhood service SM safe motherhood 
motherhood voucher package, using data on the percentage of women taking a service as observed in the Yemen NHDS implemented in 2013: ANC1, ANC2, ANC3, skilled births attended, institutional deliveries and PNC. For example, the Yemen NHDS observed that $41 \%$ of births in Lahj were attended in a health facility (institutional deliveries). We used this percentage to calculate the number of expected institutional deliveries: $41 \%$ of the 18,664 estimated total deliveries, giving 7644 expected institutional deliveries as in Table 2. We compared these results with the actual number of services utilised through the voucher programme in Lahj in 2014. For example, the actual number of institutional deliveries in Lahj by women with a voucher was 9521 , representing an increase of $25 \%$ against the expected 7644 institutional deliveries.

As illustrated in Table 2, the number of services utilised in Lahj was significantly higher than expected for all of the services that make up the safe motherhood voucher package. It should be noted that the differential in institutional deliveries is at least $25 \%$. This is because not all of the deliveries which were attended in contracted health facilities during the review period were through the voucher programme. We have counted only those deliveries which were reimbursed under the voucher scheme, but nonvoucher clients also accessed delivery services at these voucher service providers. Anecdotally, service providers reported attending non-voucher clients in approximately one quarter of total clients, so the actual difference is likely to be higher than $25 \%$.

On the supply-side, the voucher programme has brought about, and in many cases financed, the much-needed upgrading of a number of health facilities in Lahj, significantly expanding capacity for safe motherhood service delivery in the district at a time when public funds were not flowing to the governorates. For example, four health facilities (Al Anad, Ghoal Madram, Sameen and Najd Kurba) were originally contracted as health units to provide family planning services and antenatal care for the programme. They were contracted as health units which is a lower designation of facility because they did not provide institutional delivery services. During the project, these facilities have been upgraded to health centre status and recontracted in May 2014 to provide delivery services.

Using funds provided through the voucher scheme, the Kareesh Health Centre was able to contract new midwives and doctors and to start providing services $24 \mathrm{~h}$ per day, whereupon their contract was changed from a health centre to that of a Basic Emergency Obstetric and Newborn Care facility (BEmONC). Crucially, the $\mathrm{Al}$ Museymer District Hospital, which was initially contracted as a health unit because it was providing only services appropriate to this level, was able to use programme funding and be upgraded to BEmONC status, providing delivery care round the clock and complying with the seven signal functions of quality care.

\section{Discussion}

While we recognise the limitations and simplicity of this type of analysis, the paucity of census and other reliable data in Yemen, and the difficulties with collecting primary data in the context of severe security problems, means that a more sophisticated analysis is not currently an option.

However, based on our long experience of supporting and researching voucher programmes for reproductive health (Gorter et al. 2012; Grainger et al. 2014; Gorter et al. 2013), and in particular our engagement with the delivery of the voucher programme in Yemen, we have observed that vouchers can and do facilitate access to specific services when traditional supply-side approaches are unable to do so.

By linking facility reimbursements to the demand for specific services, the voucher programme was able to work on both the demand- and supply-side to improve uptake of important but underutilised health services in the target areas. In the current context of continuing instability and increasing scarcity of basic commodities in Yemen, the principal supply-side effects of the voucher programme in Yemen were to enable continued funds

Table 2 Expected uptake of safe motherhood services compared with uptake through vouchers, Lahj, 2014

\begin{tabular}{|c|c|c|c|c|}
\hline Safe motherhood services & $\begin{array}{l}\text { Expected \% women using } \\
\text { services }^{\mathrm{a}}\end{array}$ & $\begin{array}{l}\text { Expected number using } \\
\text { services }\end{array}$ & $\begin{array}{l}\text { Uptake of services through } \\
\text { vouchers }\end{array}$ & $\begin{array}{l}\text { Increase } \\
(\%)\end{array}$ \\
\hline $\mathrm{ANC}^{\mathrm{b}}$ & 67.0 & 12,491 & 16,342 & 31 \\
\hline Up to ANC2 or ANC3 & $38.7^{c}$ & 7215 & 8939 & 24 \\
\hline $\begin{array}{l}\text { Attended by skilled } \\
\text { provider }\end{array}$ & 51.8 & 9658 & 11,326 & 17 \\
\hline Institutional delivery & 41.0 & 7644 & 9521 & 25 \\
\hline $\mathrm{PNC}^{\mathrm{b}}$ & 29.0 & 5407 & 7132 & 32 \\
\hline
\end{tabular}

${ }^{a}$ National Health and Demographic Survey data for Lahj (Yemen NHDS 2015)

${ }^{\mathrm{b}} \mathrm{ANC}$ refers to ante-natal care provided during pregnancy and PNC refers to post-natal care after delivery

'This percentage is for all rural areas of Yemen; specific Lahj data for ANC2 or 3 not being available in the Yemen NHDS. All other percentages are specific for Lahj 
flow to the facilities when government funds were unreliable or ceased; continuity of service provision, even during the worst days of the crisis; the flexibility and capacity at the local level to address stock-outs of drugs and supplies; and support for quality assurance of both public and private providers.

On the demand-side, the vouchers provided an invitation to poor women and their families, often living in remote rural areas, to have an institutional delivery without the risk of incurring unpredictable and unaffordable costs, including those of travelling with a chaperone, and improved provider choice enabling women to select providers at the appropriate level of the health system as well as those closer to home.

Despite the considerable challenges of funding through government channels during the conflict, the Yemen voucher programme continued to pay providers for the services delivered, directing valuable funds to those facilities which provide not only safe motherhood services but also other much-needed basic health services. The incentives provided by the programme, in terms of both increased funding and more clients, encouraged public and private facilities to upgrade their facilities to provide quality safe motherhood services and also engaged the governorate health team to provide additional support.

Several government health facilities, including the main governorate hospital, were forced to close temporarily during the worst days of fighting. However, during these periods, women were still able to receive $\mathrm{RH}$ services from other facilities in nearby districts, including privately run midwife clinics and hospitals contracted by the voucher programme. Furthermore, financial flows through the voucher programme made it possible for public providers to buy critical supplies that were out of stock, due to interrupted supply chains affected by the ongoing conflict.

During times of intense insecurity, one would expect to see significant reductions in non-essential service delivery. For example, during the crisis of 2011 in Yemen, the World Bank-financed maternal health results-based financing project (the Queen of Sheba Project) witnessed an increase in deliveries by caesarean section and a reduction in normal deliveries at contracted private hospitals and clinics, with the likely reason that women were prepared to travel to facilities only for absolute emergencies, given the dangers of travelling by road (World Bank 2015).

UNFPA has also used vouchers to enable access to health services in fragile settings, establishing a reproductive health voucher programme inside Syria in March 2011 to allow women free access to a range of safe motherhood services, including emergency obstetric care (Ballan 2015). The vouchers are distributed to pregnant women who are internally displaced or living in conflict-affected communities by NGO mobile teams and medical professionals at facilities, and some 30,000 vouchers have been distributed since March 2011 (UNFPA 2015b). Despite the worsening conflict, 2015 saw UNFPA increase the number of contracted hospitals to 29 public and private hospitals in six governorates. ${ }^{3}$ Because of the wide range and geographical spread of participating facilities, the voucher programme has offered women a degree of choice as to where to seek treatment and has been credited with helping to maintain the health system in Syria by sustaining demand for and supply of critical health services (UNFPA 2015c).

Based on an analysis of these and other voucher programmes, we have identified below a number of lessons that are relevant for the delivery of maternal and newborn health services in other fragile and humanitarian settings:

- Voucher programmes can be set up relatively quickly and are highly flexible in their design, which is important in times of crisis. The $\mathrm{RH}$ voucher programme was piloted in the district of Tuban and was fully functioning within a period of 6 months. While all voucher programmes adhere to the same basic structure set out in Fig. 1, this structure is easily adapted to local contexts, as well as to fast-changing realities on the grounds that are particularly common in fragile settings. For example, the price of fuel and medical supplies has significantly increased during the crisis in Yemen. The programme was able to quickly adjust its pricing policy to reflect this, ensuring that providers stayed in the programme and clients continued to receive services. Once systems are set up, it is possible to contract additional providers quickly, to add new benefits to the package of subsidised services and to scale up to other geographical areas

- Maximising capacity to provide critical services to women in times of crisis is an important advantage of voucher programmes. Vouchers give suppliers reasonable confidence in the level of future demand for a given range of goods or services, and they can then invest accordingly to meet that expected demand, as demonstrated by lower-level facilities in Yemen which upgraded during the programme using reimbursement funds. The structure of voucher programmes means that they are able to leverage and increase capacity through contracting service providers from public, private for profit and nonprofit providers, in the absence of a policy framework for public-private partnership arrangements. Through careful selection of service providers, voucher programmes can provide a framework for investing in the private sector without undermining the functioning of public sector facilities, helping to 
fill gaps in provision that under-resourced and, at times, incapacitated government systems cannot address. Contracting non-state providers at the community level, such as private midwives, also potentially brings services closer to women, which is important in the context of maternal and newborn care, particularly in situations of conflict

- Where the flow of public funds has halted due to conflict or failing states, voucher programmes may be a mechanism for keeping vital funds flowing to public health providers. The elected government in Yemen has effectively been incapacitated since early 2015 and government finances severed affected since 2014. During this time, the RH voucher programme has continued to reimburse public sector providers for services, providing income for facilities and ensuring quality services continued to be available to women

- Voucher reimbursement payments incentivise both public and private providers to offer and improve targeted services that may not otherwise be as widely provided or available to women. These payments also confer a value on women in the target group, which can help to overcome the stigmatisation and discrimination routinely faced by extremely poor and marginalised women when attending health facilities

- In the absence of functioning quality assurance frameworks, voucher programmes can be used to standardise quality assurance processes and to incentivise the provision of a minimum level of service quality. In fragile and unstable environments, ministries of health often struggle to maintain the appropriate degree of oversight of service provision. Voucher programmes set quality standards for entry to the scheme and have inbuilt checks for regular quality assessment (i.e. at annual contract renewal). Well-designed programmes also provide opportunities for clients to feedback to providers through client satisfaction questionnaires, as well as mechanisms for making complaints. Voucher reimbursements can be re-invested in quality improvements

- Given the similarities in operational structures, vouchers can be and are combined with other health financing mechanisms such as conditional cash transfers and performance-based financing (PBF). Vouchers are usually added with the objective of targeting a vulnerable group or promoting uptake of an underutilised but critical service. Given that cash transfers are a common financing instrument in conflict-affected areas, (Levine and Bailey 2015), vouchers complement this approach by catalysing demand for critical health services and providing a mechanism for channelling funds to providers.

\section{Conclusion}

There is growing evidence that vouchers can increase utilisation of priority services, can improve equity and can have a positive impact on quality of services. Recent experience in Yemen has shown that vouchers are a useful tool for helping to maintain health service delivery when weakened public systems are failing to do so. This is evidenced by the success of the $\mathrm{RH}$ voucher programme in Yemen in enabling more women to access a basket of reproductive and maternal newborn health services in the context of increasing instability, a much higher than expected number of institutional deliveries (by a factor of at least 25\%) in 1 year of the crisis.

A recent report by the Center for American Progress and Save the Children Fund (SCF) (Norris et al. 2015), which examined progress towards achievement of the MDGs among a group of conflict-affected and fragile states, highlighted a number of trends from its analysis, including the fact that:

Rapid progress often seemed to occur when specific and appropriate interventions were targeted at traditionally underserved or vulnerable populations. For instance, lowering health fees, providing midwife services, or tailoring outreach to communities with low enrolment rates were types of services that tended to bode well for achieving progress (Norris et al. 2015, 6).

Voucher programmes do all these things: they target underserved populations; they can enlist the services of a range of providers to meet their needs while removing user fees at the point of delivery; they can provide additional financial support for travel and other costs associated with reaching a health facility; and they incentivise providers to tailor services to the needs of the target group.

In spite of these strengths, voucher programmes are not a health system approach and do not solve the many longer-term and entrenched challenges faced by health systems in fragile states. However, states of fragility and insecurity often give rise to short-term, urgent health needs, particularly for women and adolescents, that need to be met quickly and effectively. Vouchers are one financing mechanism available to meet these needs, and we would advocate that programme implementers in fragile settings consider vouchers as an effective means to continue to provide safe motherhood services to clients.

\section{Endnotes}

${ }^{1}$ This information is contained in un-published project design document which can be shared on request to the corresponding author. The report is entitled: Hausmann-Muela S. Introducing a voucher system for 
improving maternal health care of Aká pygmy and Bantu populations in Lobaye District, Central African Republic, Report of a planning mission and operational research design, 2013. FairMed, Berne, Switzerland.

${ }^{2}$ This information comes from a personal Communication with the former Head of Programme Unit. FairMed, Berne, Switzerland.

${ }^{3}$ This information comes from the unpublished transcript of an interview on 20 October 2015 between an independent consultant to UNFPA Kokoevi Sossouvi, and with Omar Ballan, Assistant Representative and $\mathrm{Hu}-$ manitarian Focal Point for UNFPA, Damascus, Syria.

\section{Abbreviations \\ BEmONC: Basic Emergency Obstetric and Newborn Care; CAR: Central African Republic; KfW: Kreditanstalt für Wiederaufbau; MDG: Millennium Development Goals; MENA: Middle East and North Africa; MOPHP: Ministry of Public Health and Population (Republic of Yemen); NHDS: National Health and Demographic Survey; PBF: Performance-based financing; RH: Reproductive health; SDG: Sustainable Development Goals; UNFPA: United Nations Population Fund; VMA: Voucher Management Agency}

\section{Acknowledgements}

We would like to thank the Reproductive Health Voucher Programme team in Yemen for their contributions and for their hard work under very difficult circumstances, including Asma Al-Ali, Mohammed Alzurqa and Mohammed Al Hamed. We would also thank the managing director of Yamaan Foundation for Health and Social Development, Ashraf Badr, and the director generals of Health in Lajh and lbb Governorates in Yemen, respectively, Omar Zain and Abdulmalik Alsanany, who all made the project possible. The German government, through the Development Bank Kreditanstalt für Wiederaufbau (KfW), provided the funding for the project implementation.

\section{Funding}

No funding was received by the authors for the analysis and review contained in this manuscript.

\section{Availability of data and materials}

The datasets supporting the conclusions of this article are included within the article and its additional files, and publicly available for consultation (please see for example the references: Yemen NHDS 2015 and CSO 2007).

\section{Authors' contributions}

All authors have read and approved the manuscript and all authors have contributed equally to its development.

\section{Competing interests}

The authors declare that they have no competing interests.

\section{Publisher's Note}

Springer Nature remains neutral with regard to jurisdictional claims in published maps and institutional affiliations.

\footnotetext{
Author details

${ }^{1}$ Consultant, Yemen Reproductive Health Programme, London, UK. ${ }^{2}$ Consultant, Yemen Reproductive Health Programme, Roosendaal, Netherlands. ${ }^{3}$ Options Consultancy Services Ltd, Yemen Reproductive Health Voucher Programme, Sana'a, Yemen. ${ }^{4}$ Strategy and Development Department, Marie Stopes International, London, UK.
}

Received: 11 January 2017 Accepted: 14 March 2017

Published online: 24 April 2017

\section{References}

Ballan O (2015) Reproductive health vouchers: improving women's access to emergency obstetric care in the violence affected areas in Syria, Presentation at the fifteenth annual meeting of the Inter-Agency Working Group (IAWG) on reproductive health in crises, 25-27 February, 2015, Dead Sea Region. UNFPA, Jordan

Batley R, Mcloughlin C (2010) Engagement with non-state service providers in fragile states: reconciling state-building and service delivery. Dev Policy Rev 28(2):131-154

Bellows NM, Bellows BW, Warren CE (2011) The use of vouchers for reproductive health services in developing countries: systematic review. Tropical Med Int Health 16:84-96

Brody CM, Bellows N, Campbell M, Potts M (2013) The impact of vouchers on the use and quality of health care in developing countries: a systematic review. Global Public Health 8(4):363-388

Central Statistical Organization (CSO Yemen) (2007). Yemen General Population Housing and Establishment Census 2004. Sana'a, Yemen: Central Statistical Organization (Yemen). Available http://ghdx.healthdata.org/record/yemengeneral-population-housing-and-establishment-census-2004.

Gorter AC, Bayou A (2011) Mid-Term Review: Development of the Health Sector (SWAp) Programme in Kenya- Reproductive Health Voucher Scheme (Output Based Approach) Project, Phase II, May 2011. EPOS Health Management, Bad Homburg, Germany. Available https:/www.researchgate.net/publication/ 308021490_Mid-Term_Review_Development_of_the_Health_Sector_SWAp_ Programme_in_Kenya_-Reproductive_Health_Voucher_Scheme_Output_ Based_Approach_Project_Phase_ll.

Gorter AC, Grainger C, Okal J, Bellows B (2012) Systematic review of structura and implementation issues of voucher programs, analysis of 40 voucher programs; in-depth analysis of 20 programs. Population Council, Nairobi, Available http://www.options.co.uk/sites/default/files/comprehensive_ review_of_rh_voucher_programmes.pdf.

Gorter AC, Ir P, and Meessen B. (2013) Evidence Review, Results-Based Financing of Maternal and Newborn Health Care in Low- and Lower-Middle-Income Countries. February 2013. Study commissioned and funded by the German Federal Ministry for Economic Cooperation and Development (BMZ) through the sector project PROFILE at Deutsche Gesellschaft für Internationale Zusammenarbeit (GIZ). Available http://health.bmz.de/what_we_do/ information_systems/Studies_and_articles/Results-Based-Financing-MCH/ Step_One_Evidence_Review_Gorter_et_al.pdf.

Grainger C, Gorter A, Okal J, Bellows B (2014) Lessons from sexual and reproductive health voucher program design and function: a comprehensive review. Int J Equity Health 13:33, Available http://www.equityhealthj.com/ content/13/1/33

Hanson K, Gilson L, Goodman C, Mills A, Smith R, Feachem R et al (2008) Is private health care the answer to the health problems of the world's poor? PLoS Med 5(11):e233

Kanya L. (2013) Health Facility Spending patterns of Reproductive Health Voucher Reimbursement Revenue among accredited facilities in Kenya. Presented at the International Health Economics Association Conference, Sydney, Australia, 6 July 2013, Population Council, available here: http:// healthsystemshub.org/uploads/resource_file/attachment/266/Health_ Facility_Spending_patterns_of_Health_Voucher_Reimbursement_. Revenue_in_Kenya.pdf

Levine S, Bailey S. (2015) Cash, vouchers or in-kind? Guidance on evaluating how transfers are made in emergency programming; Feb 2015. Humanitarian Policy Group, Overseas Development Institute. Available http://www.alnap. org/resource/21254.

Messner JJ, Haken N, Taft P, Blyth H, Lawrence K, Graham SP, Index FS et al (2015) The fund for peace (FFP). USA, Washington DC, Available http://library. fundforpeace.org/library/fragilestatesindex-2015.pdf

Norris J, Dunning C, Malknecht A. (2015) Fragile Progress: The Record of the Millennium Development Goals in States Affected by Conflict, Fragility, and Crisis; June 2015. Center for American Progress and Save the Children.

OCHA (2015) Office for the Coordination of Humanitarian Affairs. 2016 Humanitarian needs overview: Yemen; Nov 2015. Available http://www. unocha.org/yemen

OECD (2015) States of fragility 2015: meeting post-2015 ambitions;2015. OECD Publishing, Paris, Available http://dx.doi.org/10.1787/9789264227699-en

Temmerman M, Khosla R, Bhutta ZA, Bustreo F (2015) Towards a new global strategy for women's. Children's and Adolescents' Health BMJ 351:h4414.

UNFPA (2015b) Five years of saving lives, the United Nations Population Fund Report 2015. Available from: http://www.unfpa.org/resources/five-yearssaving-lives-regional-response-syria-crisis-2015. 
UNFPA (2015a) United Nations Population Fund (UNFPA). Women and Girls in the Syria Crisis. UNFPA Response 2015. Available https://www.unfpa.org/ sites/default/files/resource-pdf/UNFPA-FACTSANDFIGURES-5\%5B4\%5D.pdf.

UNFPA (2015c) United Nations Population Fund (UNFPA). Restoring hope... rebuilding lives. UNFPA regional response for women and girls affected by the Syria Crisis, 2015. Available https://www.unfpa.org/sites/default/files/ resource-pdf/UNFPA-ENGBROCH-SCREEN.pdf.

Watt C, Abuya T, Warren CE, Obare F, Kanya L, Bellows B (2015) Can reproductive health voucher programs improve quality of postnatal care? a quasiexperimental evaluation of Kenya's safe motherhood voucher scheme. PLoS One 10(4):e0122828, available at: http://journals.plos.org/plosone/ article?id=10.1371/journal.pone.0122828.

WHO (2015) Accountability for women and children's health, 2015 Progress Report. WHO, Geneva. Available http:/www.who.int/life-course/partners/ global-strategy/accountability-report-2015-no-isbn.pdf.

World Bank (2015) Implementation completion and results report (TF-92181) on a grant in the amount of USD 6.23 million to the Republic of Yemen for a Safe Motherhood Voucher Program, January 21, 2015. Available http://documents. worldbank.org/curated/en/801461468140387905/Yemen-Safe-MotherhoodVoucher-Program.

World Bank. Harmonized List of Fragile Situations FY15. Available http:// siteresources.worldbank.org/EXTLICUS/Resources/511777-1269623894864/ FY15FragileSituationList.pdf.

Yemen NHDS (2015) Yemen National Health and Demographic Survey 2013. Ministry of Public Health and Population and Central Statistical Organization (CSO), Government of the Republic of Yemen. Pan Arab Program for Family Health, ICF International, Rockville, Maryland, USA. Available http:// dhsprogram.com/pubs/pdf/FR296/FR296.pdf.

\section{Submit your manuscript to a SpringerOpen ${ }^{\circ}$ journal and benefit from:}

- Convenient online submission

- Rigorous peer review

- Immediate publication on acceptance

- Open access: articles freely available online

- High visibility within the field

- Retaining the copyright to your article

Submit your next manuscript at $\boldsymbol{s p r i n g e r o p e n . c o m ~}$ 